Selcuk Journal of Agriculture and Food Sciences

$\underline{\text { http://sjafs.selcuk.edu.tr/sjafs/index }}$

Review Article

\section{SJAFS}

(2021) 35 (3), 272-279

e-ISSN: $2458-8377$

DOI:10.15316/SJAFS.2021.257

\title{
Endocrine Disruptors in Baby Formulas: A Literature Review
}

\author{
iD Ozge YESILDEMIR ${ }^{1, *}$, ID Yasemin AKDEVELIOGLU ${ }^{1}$ \\ ${ }^{1}$ Gazi University, Faculty of Health Sciences, Department of Nutrition and Dietetics, Ankara, Turkey
}

\begin{tabular}{l}
\hline ARTICLE INFO \\
\hline Article history: \\
Received date: 13.07 .2021 \\
Accepted date: 07.12 .2021 \\
\hline
\end{tabular}

\section{Keywords:}

Endocrine Disruptors

Baby Formula

Bisphenol A

Pesticides

Melamine

\begin{abstract}
Baby formulas are foods designed and marketed for feeding babies. The use of baby formulas is increasing worldwide due to various reasons. In parallel, there is increasing concern about endocrine disrupting compounds (EDCs) in baby formulas. EDCs cover a large class of compounds able to interact with the endocrine system. EDCs can disrupt many different hormones, so they are linked to numerous adverse outcomes in human health. Babies are more sensitive to environmental toxins than adults. In this review, the type and amount of some EDCs in the composition of baby formulas in addition to their effects on health are examined. The evaluation of EDCs in baby formulas, which are considered a source for EDCs, has become necessary. Soy-based baby formulas are seen as a source of phytoestrogens for newborns. Organohalogens are high in especially milk-based. Pesticides are generally below the maximum limits. Phthalate levels vary depending on the package content of baby formulas. The phthalate level is higher in formulas with metal packaging. Although bisphenol A (BPA) exposure decreases with the spread of BPA-free packaging, it should be kept in mind that even very low exposures can cause significant health problems. With strict legal regulations, melamine exposure has decreased considerably. Given the susceptibility of babies to EDCs, it is essential to closely monitor the EDCs content of baby formulas.
\end{abstract}

\section{Introduction}

The health authorities suggest exclusive breastfeeding for the first six months of life and breastfeeding until at least two years of age with appropriate complementary foods after the sixth month (Lopes et al., 2018). Despite the superior characteristics of breast milk, the production and usage of baby formulas has increased due to the development of technology, industrialization, rapid change in the social role of women, increased difficulty in breastfeeding with the active role of women (Hendaus et al., 2018; Masum et al., 2020).

Baby formula market has been expected to be the fastest growing packaged food industry in recent years (Baker et al., 2021). With the boom of the baby formula market, concerns related to the presence of endocrine disrupting compounds (EDCs) in baby formulas are increasing. Fetuses, babies, and children are more vulnerable to EDCs as these substances affect the vital organs of the body and the development of the hormonal system (Kiess et al., 2021). In addition, the nervous, respiratory, and reproductive systems of babies are not fully developed. This causes some toxins to be less excreted from the body (Carroquino et al., 2013). Babies may be exposed to food chemicals at a higher rate as they consume more nutrients per body weight (de Mendonça Pereira et al., 2020). In this review, the types and quantities of endocrine disruptors in the composition and packaging of baby formulas in addition to their effects on health are examined.

\section{What are Baby Formulas?}

Although it is not possible to produce a product identical to breast milk, efforts are made to ensure growth and development in babies (Martin et al., 2016). Therefore, baby formulas are designed as an effective alternative in baby nutrition (Harris and Pomeranz, 2020). According to Codex Alimentarius guidelines, baby formula is a breast milk substitute specially manufactured to satisfy, by itself, the nutritional requirements of the babies (World Health Organization, 1981).

Baby formulas are used in the absence and inadequacy of breast milk or presence of certain metabolic diseases. Baby formulas are classified as adapted, specialized, and ready-to-feed (Rossen et al., 2016).

\section{What are Endocrine Disruptors?}

The World Health Organization (WHO) defines EDCs as exogenous substances or mixtures that induce

\footnotetext{
*Corresponding author email: ozgeyesildemir@gazi.edu.tr
} 
adverse health effects by affecting the functions of the endocrine system (World Health Organization, 2013). These substances can directly interfere with the production, release, binding, transport, destruction, and elimination of natural hormones in the body and can change their effects in the target cell. In addition, EDCs can indirectly affect the organs and systems for which they are not directly effective (Lauretta et al., 2019). Many of the EDCs are substances used to protect plants against pests. In addition, synthetic products used in the plastic industry, various building materials, and insulation materials contain EDCs (Barrios-Estrada et al., 2018). Some endocrine disruptors that can be found in baby formulas are shown in Figure 1.

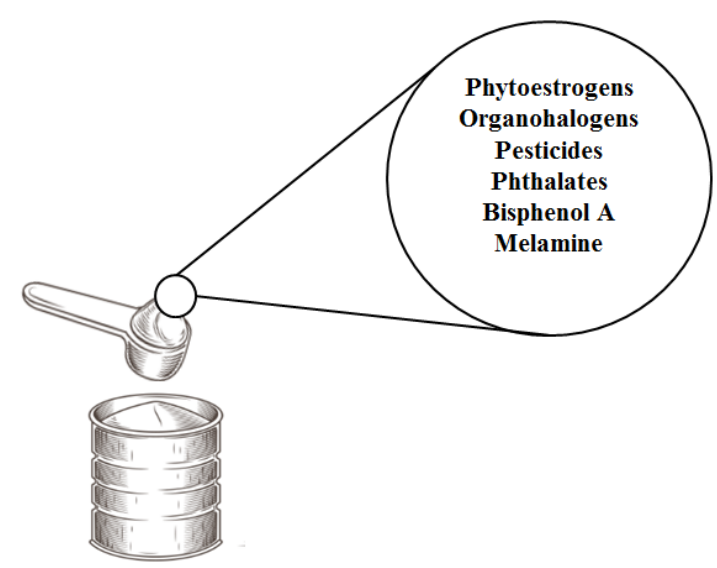

Figure 1

Some endocrine disruptors that can be found in baby formulas (Diamanti-Kandarakis et al., 2009)

\section{Endocrine Disruptors in Baby Formulas}

\subsection{Phytoestrogens}

Phytoestrogens are defined as polyphenolic compounds which are structurally or functionally similar to endogenous estrogens and synthesized by plants (Nikolić et al., 2017). Due to their structural similarity to estradiol through their phenol rings, these molecules may bind and activate the estrogen receptor promoting (anti) estrogenic effects (Gorzkiewicz et al., 2021). Phytoestrogens include classes of flavonoids, ligands, coumestan, stilbens, and zearalenone (Lecomte et al., 2017). Genistein, daidzein, and glycitein, which are among the subgroup of isoflavonoids, are the most researched phytochemicals in baby formulas, particularly soy-based formulas (Křížová et al., 2019).

There is huge interest in the effects of dietary phytoestrogens on human and animal reproductive health. It is known that very high phytoestrogen intake has negative effects on both adult female reproductive function and sexual development (Desmawati and Sulastri, 2019). Although the adverse effects of phytoestrogen on reproductive health have not been clearly demonstrated, many studies suggest that isoflavones in baby formulas have a negative effect on reproductive health in babies
(Cederroth et al., 2012). The risk of congenital malformation, cancer, malabsorption, immunological dysfunction, endocrine diseases, and neurobehavioral insufficiency increases as a result of exposure to phytoestrogens early in life (Petrine et al., 2021).

One of the ways of exposure to phytoestrogens is through soy-based baby formulas. It is known that soybased baby formulas contain poor genistein and daidzein along with their glycan forms, genistin as well as daidzin (Testa et al., 2018). Studies have shown that the concentration of isoflavones in soy-based baby formulas varies in a wide range. The total isoflavone concentration ranged from 16.2 to $85.4 \mu \mathrm{g} / \mathrm{g}$ (Fonseca et al., 2014). In the light of this information, it is known that the daily intake of the isoflavones of a baby fed soy-based formulas can rise up to $11 \mathrm{mg} / \mathrm{kg}$, which is a much higher amount than that of adults (Setchell et al., 1997). In addition, differences in isoflavone content in soy-based formulas may be due to differences in the manufacturing process, analysis methods and biological properties of the product (Westmark, 2017). Moreover, isoflavones also may be found in breast milk and milk-based formulas, but the concentration is low (Bhatia and Greer, 2008; Johns et al., 2003).

While it is a fact that soy-based baby formulas are rich sources of isoflavones, it is known that babies may effectually digest, absorb, and excrete isoflavones (Westmark, 2017). On the other hand, there are a few studies showing that urinary daidzein and genistein concentrations in babies are lower than that of adults taking the same amount of isoflavones (Cao et al., 2009; Halm et al., 2007). This can be attributed to individual differences in the maturation of the digestive ability of babies (Nguyen et al., 2015). In addition, poor renal clearance in the first period of life may also be effective (Halm et al., 2007). Therefore, more studies are needed to confirm the safety of consumption of soy-based baby formulas known to contain isoflavones early in life. In this context, the European Society for Pediatric Gastroenterology, Hepatology and Nutrition (ESPGHAN) recommends that soy-based baby formulas not be used as the only source of nutrition for children under 6 months of age (ESPGHAN, 2006).

\subsection{Organohalogen Compounds}

There are 75 different dioxins in addition to 135 different furans and 209 different polychlorinated biphenyl (PCB) varieties, which are subgroups of organohalogens in nature, 29 of which are the most toxic (Jeanjean et al., 2021). Dioxins, furans, and PCBs can be found in water, air and soil ecosystems, and food chains. Dioxins and furans are not commercially produced compounds. They often appear as undesirable by-products in the production of chemical products (Zubair and Adrees, 2019).

The adverse health effects which occur as a result of exposure to organohalogens include cancers, developmental disorders, wasting syndrome, hepatotoxicity, and renal dysplasia. They can also lead to immunotoxicity, neurotoxicity, cardiotoxicity, reproductive disorders, hypertension, and asthma (Xu et al., 2017). The main 
sources of exposure to organohalogen compounds during infancy are breast milk and baby formula (Pandelova et al., 2010).

It is set the exposure limits for dioxins and dioxinlike PCBs to 1-4 pg WHO-the equivalent toxic concentrations (TEQ) $/ \mathrm{kg}$ (body weight)/day (EFSA et al., 2018a). However, the upper range should be considered as "temporary tolerable daily intake" and it should be aimed to reduce the daily intake to below 1 WHOTEQ/kg (body weight)/day. It should be noted that the higher the dioxin intake above the specified levels, the greater the risk of cancer (World Health Organization, 1998). Studies on content of dioxins in baby formulas are very limited, and most of these studies compare breast milk and baby formulas (Hsu et al., 2007; Kerger et al., 2007; Pandelova et al., 2010). Although dioxin exposure is higher in breastfed babies compared to formula-fed babies, formula feeding should not be recommended instead of breastfeeding for low dioxin exposure, considering the benefits of breast milk (Pandelova et al., 2010).

Furan, a colorless, volatile, and lipophilic component, is classified as a carcinogen for humans by the International Agency for Research on Cancer (IARC). The primary source of furan in foods is considered to be the thermal degradation of carbohydrates such as glucose, lactose, and fructose (Javed et al., 2021). Furan, which is ingested and inhaleted, is rapidly absorbed and extensively metabolised. It is known to cause adverse health effects on the liver and kidneys (Javed et al., 2021; Li et al., 2020).

There are many studies to determine the furan levels in baby formulas. According to these studies, furan levels in baby formulas increased from undetectable levels to $28.7 \mathrm{ng} / \mathrm{g}$ (Lambert et al., 2018; Liu and Tsai, 2010; Nie et al., 2013). The European Food Safety Authority (EFSA) (2004) reported that furan levels ranged from undetectable levels to $112 \mathrm{ng} / \mathrm{g}$ in analyzes on 273 baby formulas. Baby formulas for milk protein allergy have relatively higher furan levels than other formulas. It is thought that furans may occur during spray drying or hydrolysis while the protein is hydrolyzed (Pandelova et al., 2010). Furan formation in baby formulas is a serious food safety problem. The new production techniques should be developed to prevent furan formation as a result of heat treatment in baby formulas (Javed et al., 2021).

PCBs are also one of the EDCs which can be found anywhere and classified as carcinogens. However, the number of studies examining PCB levels in baby formulas is very low (Agathokleous et al., 2018). In a study, 174 breast milk samples, 16 cow's milk samples, and 6 baby formula samples were analyzed and the lowest concentration PCBs were found in baby formulas (Pietrzak-Fiećko et al., 2005). As the PCB levels in cow's milk are generally higher than in baby formulas, most of the lipids of animal origin are deliberately removed from milk based formulas and are replaced with vegetable oil with relatively low PCBs content (Mahmoud et al.,
2021). However, in all cases the exposure of PCBs appears to remain below the determined maximum levels. Baby formulas are not thought to be a risk factor for PCBs, but it should be taken into account that exposure of PCBs will increase with complementary feeding (Lorán et al., 2009).

\subsection{Pesticides}

Pesticides are synthetic chemical compounds used to eliminate pests such as unwanted plants, insects, rodents, and fungi (Malik and Kumar, 2021). Humans can exposure to pesticides through dermal, inhalation, or ingestion. Pesticides cause acute effects and many chronic effects such as poisoning, neurotoxicity, developmental disorders, as well as cancer in children (Kapsi et al., 2019).

Considering that baby formulas are produced from dried hydrolyzed cow's milk or soybean, or that modifications are applied to make the protein more digestible, it is predicted that pesticides are transmitted by contamination (Westmark, 2017). The maximum residue limit (MRL) of pesticides in foods should be determined in legal regulations and kept under control. For this reason, the European Commission (2006) set MRL of 0.01 $\mathrm{mg} / \mathrm{kg}$ for each pesticide in baby foods. In addition, the use of several highly toxic pesticides has been limited and some pesticides have been banned in agricultural products used in the production of baby formulas. More recently, EFSA (2018b) recommended that MRL for pesticide should be below $0.01 \mathrm{mg} / \mathrm{kg}$ for infants younger than 16 weeks.

In most studies to determine the pesticide residue in baby formulas, the pesticide levels remained below detectable limits (Dobrinas et al., 2016; Kilic et al., 2018). The absence of pesticides in milk-based baby formulas may be a result of the fact that the used milk was a mixture of milk varieties of different origins, causing a dilution of any pesticide contamination. In addition, pesticide concentrations may decrease as a result of heat treatment (Melgar et al., 2010).

\subsection{Phthalates}

Phthalates are one of the most widely produced organic chemical classes in the world as their annual production is reached approximately 8 million tons (Wang et al., 2019). Diesters of 1,2-benzenedicarboxylic acid, commonly known as phthalates, are a group of industrial chemicals used mostly in the production of polyvinyl chloride (PVC) and as a plasticizer in the synthesis of a small number of other polymers (Giuliani et al., 2020). Various types of plastic tubing are widely used to transport milk, and PVC is included in the packaging of foods as well as baby formulas in several countries (Mankidy et al., 2013).

When phthalates enter the organism, they are hydrolyzed to monoesters and later oxidized in complex ways. Although it is not clear which molecules are more toxic, many studies have shown that exposure to phthalates negatively affects sexual characteristics. Also, phthalates can alter the deoxyribonucleic acid (DNA) 
methylation and therefore transmit these effects to future generations (Dutta et al., 2020).

The maximum contaminant level (MCL) set by the Food and Drug Administration (FDA) (2012) for DEHP is 0.006 milligram per liter. Based on its adverse effects on animals, the oral reference dose (RfD) established by the Environmental Protection Agency (EPA) for DBP is $0.1 \mathrm{mg} / \mathrm{kg} / \mathrm{day}$. The recommended RfD for DEHP is $0.02 \mathrm{mg} / \mathrm{kg} / \mathrm{day}$. According to the European Scientific Committee on Toxicity, Ecotoxicity, and the Environment (EU-CSTEE), in addition to the Scientific Committee on Food (EU-SCF), the maximum acceptable daily intake is equal to $50 \mu \mathrm{g} / \mathrm{kg}$ (body weight), whereas a lower acceptable dose $(22 \mu \mathrm{g} / \mathrm{kg}$ (body weight) was proposed by EPA (Del Bubba et al., 2018).

When the phthalate content of four ready-to-feed formulas commercially available in the Italian market was examined, it was found that the detectability of all phthalate types was $100 \%$. Assuming an infant body weight of $5 \mathrm{~kg}$ and daily milk feeding of $800 \mathrm{~mL}$, the equivalent DEHP intake for baby formulas was in the range of $21-45 \mu \mathrm{g} / \mathrm{kg}$ (body weight). The equivalent DEHP intake for all baby formulas remained above the EPA recommendation limits, while below EU-CSTEE and EU-SCF (Del Bubba et al., 2018). Apart from this study, there are a small number of studies detecting phthalate concentration in baby formulas (Cirillo et al., 2015; Ge et al., 2016). However, the phthalate levels in baby formulas vary widely in these studies. This difference may be caused by the content of the product, production processes, packaging materials, and storage conditions. Generally, phthalate levels in metal packaged products are much lower than in plastic packaged products (Ge et al., 2016).

\subsection{Bisphenol A}

Bisphenol A (BPA), 2,2-bis (27 4-hydroxyphenyl) propane, is an estrogenic compound and a synthetic substance used in polycarbonate in addition to epoxy resins (Iyigundogdu et al., 2020). The most important source of exposure to BPA is nutrition as a result of the migration of the BPA monomer from the packaging (Almeida et al., 2018). Baby formula packaging containing BPA has been banned in Europe since March 2011 (European Commission, 2011).

BPA is associated with reproductive system cancers, fertility problems, and other endocrine disorders. Most of the estrogenic effects caused by BPA have been reported to occur at concentrations below the recommended safe daily exposure (Ribeiro et al., 2017).

The total daily intake set by EFSA (2015) for BPA has been $4 \mu \mathrm{g} / \mathrm{kg} /$ day since January 2015 . Also, the specific migration limit (SML) is determined $0.05 \mathrm{mg} / \mathrm{kg}$ (EFSA, 2015). BPA was detected in 4 of the 10 baby formulas taken from different supermarkets in Camerino (Italy) and Valencia (Spain). The mean of samples was determined in a range of $0.07-1.29 \mathrm{mg} / \mathrm{kg}$ (Ferrer et al., 2011). Shao et al. (2007) found a positive sample from 10 powdered baby formula samples and determined the amount as $0.49 \mathrm{mg} / \mathrm{kg}$. The BPA content of baby formulas should be monitored regularly to ensure the safety of infants (Karsauliya et al., 2021).

\subsection{Melamine}

Melamine (2,4,6-triamino-1,3,5-triazine) is a nitrogen-rich industrial chemical produced in high volumes (Wu et al., 2016). Products made of melamine-formaldehyde plastic can also be found in food as a result of use in materials, including box coatings, paper, cardboard, and adhesives (Ebner et al., 2020). It is illegally used in food or feed products to increase the content of the false protein (Rajpoot et al., 2020).

Interest in melamine first began with the death of many pets due to kidney failure in 2007. Scientists observed melamine contamination in pet foods. Later, in 2008, thousands of Chinese babies and young children were hospitalized with urine problems due to the consumption of melamine-contaminated baby formulas and related dairy products (Gossner et al., 2009).

The current SML for plastics, as specified in the European Union legislation, is $2.5 \mathrm{mg} / \mathrm{kg}$ (European Commission, 2019). The MRLs are set for different products in many countries. Many countries state that baby formulas must not contain melamine (Wen et al., 2016). In addition, the tolerable daily intake set by WHO for melamine is $0.2 \mathrm{mg} / \mathrm{kg}$ (World Health Organization, 2015).

Deabes and El-Habib (2012) evaluated the melamine content in 22 samples, including baby formula, followon milk, and whole milk powder. Melamine was detected in all samples, and the highest melamine content $(258 \mathrm{mg} / \mathrm{kg})$ was in baby formulas. In a study conducted in Iran, melamine in baby formulas was found to be 1.38 $\mathrm{mg} / \mathrm{kg}$ (Poorjafari et al., 2015). In another Canadian study, melamine was detected in 71 of 94 baby formulas in concentrations ranging from $4.31-346 \mu \mathrm{g} / \mathrm{kg}$ (Tittlemier et al., 2009). Recent studies have shown that infants' daily melamine intake is lower than the tolerable daily intake (Zheng et al., 2020; Zhu and Kannan, 2018). However, there is a risk of nephrolithiasis even in intakes below the tolerable daily intake. Therefore, the debate about the tolerable daily intake of melamine continues (Wu and Zhang, 2013).

\section{Conclusions}

Clinical studies on the effects of phytoestrogens on baby health are insufficient. There are no published opinions of international organizations regarding the maximum limits of phytoestrogens in baby formulas. Both the American Academy of Pediatrics and the ESPGHAN reported that there is little data for the safe use of soy-based formulas in baby nutrition. For this reason, it may be recommended to conduct clinical trials, especially regarding phytoestrogens in soy-based baby formulas. Since the MRL of pesticides in baby formulas has been determined, the probability of pesticides is very low, or the detected amounts are generally below the MRL. Powdered baby formulas packaged with containers including phthalates are considered risky for 
phthalates. For this reason, legal limits should be determined for the packaging materials used in baby formulas. In addition, after the baby formulas are produced, they should be evaluated in terms of maximum limits at the expiry date. In recent years, the presence of BPA in baby formulas has decreased due to the tendency to use BPA-free coatings. However, considering the long shelf life and high lipid content of baby formulas, it cannot eliminate the health risks of BPA. The amount of melamine in baby formulas that will be reliable is quite controversial. The safety of baby formulas should be handled internationally due to the death and health problems caused by melamine in various countries. It is inevitable that every event in this matter has an international dimension.

Consequently, given the importance of baby nutrition, it is necessary to set legal limits for EDCs in baby formulas and routine checks to detect them. In addition, consumers should not forget the importance of healthy and reliable infant formulas. Consumers should pay attention to the food label, ingredient list, shelf life, special storage and instructions of use when purchasing baby formula.

\section{References}

Agathokleous E, Kitao M, Calabrese EJ (2018). Environmental hormesis and its fundamental biological basis: Rewriting the history of toxicology, Environmental Research, 165, 274-278.

Almeida S, Raposo A, Almeida-González M, Carrascosa C (2018). Bisphenol A: Food exposure and impact on human health, Comprehensive Reviews in Food Science and Food Safety, 17(6), 1503-1517.

Baker P, Russ K, Kang M, Santos TM, Neves PA, Smith J, Kingston G, Mialon M, Lawrence M, Wood B, Moodie R, Clark D, Sievert K, Boatwright M, McCoy D (2021). Globalization, first-foods systems transformations and corporate power: a synthesis of literature and data on the market and political practices of the transnational baby food industry, Globalization and Health, 17(1), 1-35.

Barrios-Estrada C, de Jesus Rostro-Alanis M, MuñozGutiérrez BD, Iqbal HM, Kannan S, Parra-Saldivar R (2018). Emergent contaminants: Endocrine disruptors and their laccase-assisted degradation-A review, Science of the Total Environment, 612, 1516-1531.

Bhatia J, Greer F (2008). Use of soy protein-based formulas in infant feeding, Pediatrics, 121(5), 10621068.

Cao Y, Calafat AM, Doerge DR, Umbach DM, Bernbaum JC, Twaddle NC, Ye X, Rogan WJ (2009). Isoflavones in urine, saliva, and blood of infants: data from a pilot study on the estrogenic activity of soy formula, Journal of Exposure Science \& Environmental Epidemiology, 19(2), 223-234.
Carroquino MJ, Posada M, Landrigan P (2013). Environmental toxicology: children at risk. Louisiana: Springer, 239-291.

Cederroth CR, Zimmermann C, Nef S (2012). Soy, phytoestrogens and their impact on reproductive health, Molecular and Cellular Endocrinology, 355(2), 192-200.

Cirillo T, Latini G, Castaldi MA, Dipaola L, Fasano E, Esposito F, Scognamiglio G, Di Francesco F, Cobellis L (2015). Exposure to di-2-ethylhexyl phthalate, di-n-butyl phthalate and bisphenol A through infant formulas, Journal of Agricultural and Food Chemistry, 63(12), 3303-3310.

de Mendonça Pereira BF, de Almeida CC, Leandro K C, da Costa MP, Conte-Junior CA, Spisso BF (2020). Occurrence, sources, and pathways of chemical contaminants in infant formulas, Comprehensive Reviews in Food Science and Food Safety, 19(4), 1378-1396.

Deabes M, El-Habib R (2012). Determination of melamine in infant milk formula, milk powder and basaa fish samples by HPLC/DAD, Journal of Environmental and Analytical Toxicology, 2(4), 1-4.

Del Bubba M, Ancillotti C, Checchini L, Fibbi D, Rossini D, Ciofi L, Rivoira L, Profeti C, Orlandini S, Furlanetto S (2018). Determination of phthalate diesters and monoesters in human milk and infant formula by fat extraction, size-exclusion chromatography clean-up and gas chromatographymass spectrometry detection, Journal of Pharmaceutical and Biomedical Analysis, 148, 6-16.

Desmawati D, Sulastri D (2019). Phytoestrogens and their health effect, Open Access Macedonian Journal of Medical Sciences, 7(3), 495.

Diamanti-Kandarakis E, Bourguignon JP, Giudice LC, Hauser R, Prins GS, Soto AM, Zoeller RT, Gore AC (2009). Endocrine-disrupting chemicals: an Endocrine Society scientific statement, Endocrine Reviews, 30(4), 293-342.

Dobrinas S, Soceanu A, Popescu V, Coatu V (2016). Polycyclic aromatic hydrocarbons and pesticides in milk powder, The Journal of Dairy Research, 83(2), 261.

Dutta S, Haggerty DK, Rappolee DA, Ruden DM (2020). Phthalate exposure and long-term epigenomic consequences: A review, Frontiers in Genetics, 11, 405.

Ebner I, Haberer S, Sander S, Kappenstein O, Luch A, Bruhn T (2020). Release of Melamine and Formaldehyde from Melamine-Formaldehyde Plastic Kitchenware, Molecules, 25(16), 3629.

EFSA Panel on Food Contact Materials, Enzymes, Flavourings and Processing Aids (CEF) (2015). Scientific Opinion on the risks to public health related to the presence of bisphenol A (BPA) in foodstuffs: Part I-Exposure assessment. EFSA Journal, 13, 3978. 
EFSA Panel on Contaminants in the Food Chain (CONTAM) (2018a). Risk for animal and human health related to the presence of dioxins and dioxinlike PCBs in feed and food, EFSA Journal, 16(11), 05333.

EFSA Panel on Plant Protection Products and their Residues (PPR) (2018b). Scientific opinion on pesticides in foods for infants and young children, EFSA Journal, 16(6), 05286.

ESPGHAN Committee on Nutrition, Agostoni C, Axelsson I, Goulet O, Koletzko B, Michaelsen KF, Puntis J, Rieu D, Rigo J, Shamir R, Szajewska H, Turck D (2006). Soy protein infant formulae and follow-on formulae: a commentary by the ESPGHAN committee on nutrition. Journal of Pediatric Gastroenterology and Nutrition, 42(4), 352-361.

European Commission (2006). Commission Directive 2006/125/EC of 5 December 2006 on processed cereal-based foods and baby foods for infants and young children, Official Journal of the European Union, 339, 16-35.

European Commission (2011). Bisphenol A: EU ban on baby bottles to enter into force tomorrow.

European Commission (2019) Commission Recommendation (EU) 2019/794 of 15 May 2019 on a coordinated control plan with a view to establishing the prevalence of certain substances migrating from materials and articles intended to come into contact with food, Official Journal of the European Union, 129, 37-42.

European Food Safety Authority (EFSA) (2004). Report of the CONTAM Panel on provisional findings on furan in food, EFSA Journal, 2(12), 137.

Ferrer E, Santoni E, Vittori S, Font G, Mañes J, Sagratini G (2011). Simultaneous determination of bisphenol A, octylphenol, and nonylphenol by pressurised liquid extraction and liquid chromatography-tandem mass spectrometry in powdered milk and infant formulas, Food Chemistry, 126(1), 360-367.

Fonseca ND, Villar MPM, Donangelo CM, Perrone D (2014). Isoflavones and soyasaponins in soy infant formulas in Brazil: profile and estimated consumption, Food Chemistry, 143, 492-498.

Food and Drug Administration (2012). Guidance for industry limiting the use of certain phthalates as excipients in CDER-regulated products. New Hampshire: Silver Spring (MD).

Ge W, Yang X, Wu X, Wang Z, Geng W, Guo C (2016). Phthalate residue in goat milk-based infant formulas manufactured in China, Journal of Dairy Science, 99(10), 7776-7781.

Giuliani A, Zuccarini M, Cichelli A, Khan H, Reale M (2020). Critical review on the presence of phthalates in food and evidence of their biological impact, International Journal of Environmental Research and Public Health, 17(16), 5655.
Gorzkiewicz J, Bartosz G, Sadowska-Bartosz I (2021). The Potential Effects of Phytoestrogens: The Role in Neuroprotection, Molecules, 26(10), 2954.

Gossner CME, Schlundt J, Ben Embarek P, Hird S, LoFo-Wong D, Beltran JJO, Teoh KN, Tritscher A (2009). The melamine incident: implications for international food and feed safety, Environmental Health Perspectives, 117(12), 1803-1808.

Halm BM, Ashburn LA, Franke AA (2007). Isoflavones from soya foods are more bioavailable in children than adults, British Journal of Nutrition, 98(5), 9981005.

Harris JL, Pomeranz JL (2020). Infant formula and toddler milk marketing: opportunities to address harmful practices and improve young children's diets, Nutrition Reviews, 78(10), 866-883.

Hendaus MA, Alhammadi AH, Khan S, Osman S, Hamad A (2018). Breastfeeding rates and barriers: a report from the state of Qatar, International Journal of Women's Health, 10, 467.

Hsu JF, Guo YL, Liu CH, Hu SC, Wang JN, Liao PC (2007). A comparison of PCDD/PCDFs exposure in infants via formula milk or breast milk feeding, Chemosphere, 66(2), 311-319.

Iyigundogdu I, Ustundag A, Duydu Y (2020). Toxicological evaluation of bisphenol A and its analogues, Turkish Journal of Pharmaceutical Sciences, 17(4), 457-462.

Javed F, Shahbaz HM, Nawaz A, Olaimat AN, Stratakos AC, Wahyono A, Munir S, Muenn-ud-din G, Ali Z, Park J (2021). Formation of furan in baby food products: Identification and technical challenges, Comprehensive Reviews in Food Science and Food Safety, 20, 2699-2715.

Jeanjean M, Goix S, Periot M, Douib K, Dron J, Etienne MP, Marchand P, Austruy A, Revenko G, Chamaret $P$ (2021). Environmental and Dietary Exposures Near a Major Industrial Harbour (Fos-sur-Mer, France) Identified as a Significant Pathway for PCBs and PCDD/Fs Accumulation in Residents' Blood Serum, Exposure and Health, 13, 447-464.

Johns P, Dowlati L, Wargo W (2003). Determination of isoflavones in ready-to-feed soy-based infant formula, Journal of AOAC International, 86(1), 7278.

Kapsi M, Tsoutsi C, Paschalidou A, Albanis T (2019). Environmental monitoring and risk assessment of pesticide residues in surface waters of the Louros River (N.W. Greece), Science of the Total Environment, 650(2), 2188-2198.

Karsauliya K, Bhateria M, Sonker A, Singh SP (2021). Determination of bisphenol analogues in infant formula products from India and evaluating the health risk in infants asssociated with their exposure, Journal of Agricultural and Food Chemistry, 69(13), 3932-3941. 
Kerger BD, Leung HW, Scott PK, Paustenbach DJ (2007). Refinements on the age-dependent half-life model for estimating child body burdens of polychlorodibenzodioxins and dibenzofurans, Chemosphere, 67(9), 272-278.

Kiess W, Häussler G, Vogel M (2021). Endocrinedisrupting chemicals and child health, Best Practice \& Research Clinical Endocrinology \& Metabolism, 35(5), 101516.

Kilic S, Tongur T, Kilic M, Erkaymaz T (2018). Determination of some endocrine-disrupting metals and organochlorinated pesticide residues in baby food and infant formula in Turkish markets, Food Analytical Methods, 11(12), 3352-3361.

Kř́žzvá L, Dadáková K, Kašparovská J, Kašparovský T (2019). Isoflavones, Molecules, 24(6), 1076.

Lambert M, Inthavong C, Desbourdes C, Hommet F, Sirot V, Leblanc JC, Hulin M, Guérin T (2018). Levels of furan in foods from the first French Total Diet Study on infants and toddlers, Food Chemistry, 266, 381-388.

Lauretta R, Sansone A, Sansone M, Romanelli F, Appetecchia M (2019). Endocrine disrupting chemicals: effects on endocrine glands, Frontiers in Endocrinology, 10, 178.

Lecomte S, Demay F, Ferrière F, Pakdel F (2017). Phytochemicals targeting estrogen receptors: Beneficial rather than adverse effects? International Journal of Molecular Sciences, 18(7), 1381.

Li H, Yang H, Li P, Li M, Yao Q, Min L, Zhang Y, Wang J, Zheng N (2020). Maillard reaction products with furan ring, like furosine, cause kidney injury through triggering ferroptosis pathway, Food Chemistry, 319, 126368.

Liu YT, Tsai SW (2010). Assessment of dietary furan exposures from heat processed foods in Taiwan, Chemosphere, 79(1), 54-59.

Lopes WC, Marques FKS, de Oliveira CF, Rodrigues JA, Silveira MF, Caldeira AP, de Pinho L (2018). Infant feeding in the first two years of life, Revista Paulista de Pediatria, 36(2), 164.

Lorán S, Conchello P, Bayarri S, Herrera A (2009). Evaluation of daily intake of PCDD/Fs and indicator PCBs in formula-fed Spanish children, Food Additives and Contaminants, 26(10), 1421-1431.

Mahmoud MA, Abdel-Mohsein H, Mahmoud U, Lyu Z, Soleman SR, Li M, Fujitani T, Sassa MH, Fujii Y, Cao Y, Hitomi T, Harada KH (2021). Systematic Review Protocol for the Current State of Chemical Exposure in Infants via Breast Milk, Artificial Milk and Dairy Products, International Journal of Environmental Research and Public Health, 18(9), 4436.

Malik A, Kumar G (2021). An overview of chemical pesticides and its impact on environment and human health, International Journal of Modern Agriculture, 10(2), 2045-2052.
Mankidy R, Wiseman S, Ma H, Giesy JP (2013). Biological impact of phthalates, Toxicology Letters, 217(1), 50-58.

Martin CR, Ling PR, Blackburn GL (2016). Review of infant feeding: key features of breast milk and infant formula, Nutrients, 8(5), 279.

Masum A, Chandrapala J, Huppertz T, Adhikari B, Zisu B (2020). Production and characterization of infant milk formula powders: A review, Drying Technology, 39(11), 1492-1512.

Melgar MJ, Santaeufemia M, Garcia MA (2010). Organophosphorus pesticide residues in raw milk and infant formulas from Spanish northwest, Journal of Environmental Science and Health, Part B, 45(7), 595-600.

Nguyen TT, Bhandari B, Cichero J, Prakash S (2015). A comprehensive review on in vitro digestion of infant formula, Food Research International, 76, 373-386.

Nie S, Huang J, Hu J, Zhang Y, Wang S, Li C, Marcone M, Xie M (2013). Effect of $\mathrm{pH}$, temperature and heating time on the formation of furan in sugarglycine model systems, Food Science and Human Wellness, 2(2), 87-92.

Nikolić IL, Savić-Gajić IM, Tačić AD, Savić IM (2017). Classification and biological activity of phytoestrogens: A review, Advanced Technologies, 6(2), 96-106.

Pandelova M, Piccinelli R, Kasham S, Henkelmann B, Leclercq C, Schramm KW (2010). Assessment of dietary exposure to PCDD/F and dioxin-like PCB in infant formulae available on the EU market, Chemosphere, 81(8), 1018-1021.

Petrine JC, Del Bianco-Borges B (2021). The influence of phytoestrogens on different physiological and pathological processes: An overview, Phytotherapy Research, 35(1), 180-197.

Pietrzak-Fiećko R, Smoczyńska K, Smoczyński S (2005). Polychlorinated biphenyls in human milk, UHT cow's milk and infant formulas, Polish Journal of Environmental Studies, 14, 237-241.

Poorjafari N, Zamani A, Mohseni M, Parizanganeh A (2015). Assessment of residue melamine in dairy products exhibited in Zanjan market, Iran by highperformance liquid chromatography method, International Journal of Environmental Science and Technology, 12(3), 1003-1010.

Rajpoot M, Bhattacharya R, Sharma S, Gupta S, Sharma V, Sharma AK (2020). Melamine contamination and associated health risks: Gut microbiota does make a difference, Biotechnology and Applied Biochemistry.

Ribeiro, E, Ladeira C, Viegas S (2017). Occupational exposure to bisphenol A (BPA): a reality that still needs to be unveiled, Toxics, 5(3), 22.

Rossen LM, Simon AE, Herrick KA (2016). Types of infant formulas consumed in the United States, Clinical Pediatrics, 55(3), 278-285. 
Setchell KD, Zimmer-Nechemias L, Cai J, Heubi JE (1997). Exposure of infants to phyto-oestrogens from soy-based infant formula, The Lancet, 350(9070), 23-27.

Shao B, Han H, Tu X, Huang L (2007). Analysis of alkylphenol and bisphenol A in eggs and milk by matrix solid phase dispersion extraction and liquid chromatography with tandem mass spectrometry, Journal of Chromatography B: Analytical Technologies in the Biomedical and Life Sciences, 850(1-2), 412-416.

Testa I, Salvatori C, Di Cara G, Latini A, Frati F, Troiani S, Principi N, Esposito S (2018). Soy-based infant formula: are phyto-oestrogens still in doubt? Frontiers in Nutrition, 5, 110.

Tittlemier SA, Lau BP, Menard C, Corrigan C, Sparling M, Gaertner D, Pepper G, Feeley M (2009). Melamine in infant formula sold in Canada: occurrence and risk assessment, Journal of Agricultural and Food Chemistry, 57(12), 53405344.

Wang Y, Zhu H, Kannan K (2019). A review of biomonitoring of phthalate exposures, Toxics, 7(2), 21.

Wen JG, Liu XJ, Wang ZM, Li TF, Wahlqvist ML (2016). Melamine-contaminated milk formula and its impact on children, Asia Pacific Journal of Clinical Nutrition, 25(4), 697.

Westmark CJ (2017). Soy-based therapeutic baby formulas: testable hypotheses regarding the pros and cons, Frontiers in Nutrition, 3, 59.

World Health Organization (1981). CODEX alimentarius: standard for infant formula and formulas for special medical purposes intended for infants. Geneva.
World Health Organization (1998). Assessment of the health risk of dioxins: re-evaluation of the Tolerable Daily Intake (TDI). WHO Consultation, Geneva.

World Health Organization (2013). State of the science of endocrine disrupting chemicals-2012. Geneva.

World Health Organization (2015). Experts set tolerable level for melamine intake. Geneva.

Wu T, Chen H, Lin Z, Tan C (2016). Identification and quantitation of melamine in milk by near-infrared spectroscopy and chemometrics, Journal of Spectroscopy.

Wu Y, Zhang Y (2013). Analytical chemistry, toxicology, epidemiology and health impact assessment of melamine in infant formula: recent progress and developments, Food and Chemical Toxicology, 56, 325-335.

$\mathrm{Xu}$ F, Tay JH, Covaci A, Padilla-Sánchez JA, Papadopoulou E, Haug LS, Neels H, Sellström U, de Wit CA (2017). Assessment of dietary exposure to organohalogen contaminants, legacy and emerging flame retardants in a Norwegian cohort, Environment International, 102, 236-243.

Zheng G, Boor BE, Schreder E, Salamova A (2020). Exposure to melamine and its derivatives in childcare facilities, Chemosphere, 244, 125505.

Zhu H, Kannan K (2018). Continuing occurrence of melamine and its derivatives in infant formula and dairy products from the United States: Implications for environmental sources, Environmental Science \& Technology Letters, 5(11), 641-648.

Zubair M, Adrees A (2019). Dioxins and Furans: Emerging Contaminants of Air. In J Del Real-Olvera (Ed.), Air pollution. IntechOpen. 